\title{
Biological Emergency Management: The Case of Ebola 2014 and the Air Transportation Involvement
}

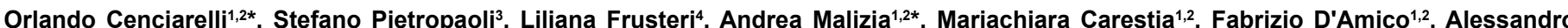
Sassolini ${ }^{1}$, Daniele Di Giovanni ${ }^{1,2}$, Annalaura Tamburrini ${ }^{6}$, Leonardo Palombi ${ }^{2,5}$, Carlo Bellecci ${ }^{1,2}$ and Pasquale Gaudio ${ }^{1,2}$

${ }^{1}$ Department of Industrial Engineering, University of Rome Tor Vergata, Rome, Italy

${ }^{2}$ Scientific Board of the International Master Courses in Protection Against CBRNe events, Department of Industrial Engineering and School of Medicine and Surgery, University of Rome Tor Vergata, Rome, Italy

${ }^{3}$ Department of Science, University of Rome 3, Rome, Italy

${ }^{4}$ Technical Advisory for Risk Assessment and Prevention, Italian Workers' Compensation Autohority, Rome, Italy

${ }^{5}$ Department of Bio-Medical \& Prevention, School of Medicine and Surgery, University of Rome Tor Vergata, Rome, Italy

${ }^{6}$ International Master Courses in Protection Against CBRNe events, Department of Industrial Engineering and School of Medicine and Surgery, University of Rome Tor Vergata, Rome, Italy

\begin{abstract}
The putative spread after the outbreak of the haemorrhagic fever epidemic caused by Ebola virus in West Africa, in the early months of 2014, puts the spotlight on the management of biological risks involving air transportation. Ebola virus is a highly pathogenic agent, causing a haemorrhagic fever defined Ebola HF, characterized by a high fatality. This virus is generally considered to be self-limiting in terms of diffusion; its lethality is in fact so high as to prevent the exit from rural areas where outbreaks generally occur. However, when the virus comes from rural areas and reaches urban places, it is important to assess the risk of spreading even in areas far from the outbreak of origin. Therefore, the development or strengthening of strategies and plans to take action with timely and effective response in order to reduce the consequences of public health emergencies is paramount. During Ebola virus outbreak in West Africa in 2014, World Health Organization focused attention on many airports, stops of main flights coming from Africa; the aviation, due to its nature, has the potential to help boost the global spread of transmissible diseases, since air travel allow to reach the most remote locations in hours.
\end{abstract}

The management of biological emergencies during ordinary operations of airlines and airports represents a real constraint in the event of contrast epidemic situations or endemic outbreaks. An effective response plan should include a careful assessment of the risks and the establishment of procedures to carry on board of aircrafts or on the ground.

To ensure that this complex system works correctly, a broad and effective cooperation between the different actors involved is required. On the international level, several documents and recommendations relating to the management of contagious diseases in aeronautical environment have been produced by authoritative agencies.

In this paper, after an overview on the international response to public health emergencies in the aviation environment, the attention is focused on emergency response to the Ebola virus crisis in 2014, including an evaluation of the potential dispersion of the pathogen.

Keywords: Ebola virus outbreak; Haemorrhagic fever; West Africa; Guinea; Aviation

\section{Introduction}

Ebola virus is currently regarded as the most lethal virus so far discovered, causing severe haemorrhagic fever disease and high casefatality rates. This high fatality, combined with the absence of treatment and vaccination options [1], makes Ebola virus an important public health pathogen. The underestimation of the severity of a possible epidemic or pandemic situation could represent a catastrophic mistake. Ebola viruses belong, together with Marburgvirus, to the family of Filoviridae: these cause a severe haemorrhagic fever in humans and non-human primates. A novel Ebola virus-like virus, discovered in $M$. schreibersii in Cueva del Lloviu in Spain, named Cuevavirus, has been proposed recently as new genus of Filoviridae family [2].

Filoviruses are enveloped, non-segmented, negative stranded RNA viruses. Ebola virus particles have an uniform diameter of $80 \mathrm{~nm}$, but they can greatly vary in morphology including long, up to $14 \mu \mathrm{m}$, sometimes branched filaments, as well as shorter filaments shaped like a "6", a "U", or a circle. The genome, approximately $19 \mathrm{~kb}$ in size, consists of seven genes, linearly arranged, that are sequentially transcribed by
RNA polymerase complex (L and VP35 proteins) recognition of start and stop signals flanking each viral gene. The inner ribonucleoprotein complex of virion particles consists of the RNA genome encapsulated by the nucleoprotein $(\mathrm{N})$, which associates with VP30 and the RNA polymerase complex. VP40 in association with VP24 serves as the matrix protein and mediates particle formation. The glycoprotein GP

*Corresponding authors: Orlando Cenciarelli, Department of Industrial Engineering, University of Rome "Tor Vergata", Via del Politecnico 1 - 00133 Rome, Italy, Tel: +39 067259 7198; E-mail: orlando.cenciarelli@uniroma2.it

Andrea Malizia, Department of Industrial Engineering, University of Rome "Tor Vergata”, Via del Politecnico 1-00133 Rome, Italy, Tel: +39 0672597201; E-mail: malizia@ing.uniroma2.it

Received May 16, 2014; Accepted June 04, 2014; Published June 11, 2014

Citation: Cenciarelli O, Pietropaoli S, Frusteri L, Malizia A, Carestia M, et al. (2014) Biological Emergency Management: The Case of Ebola 2014 and the Air Transportation Involvement. J Microb Biochem Technol 6: 247-253. doi:10.4172/1948-5948.1000152

Copyright: (c) 2014 Cenciarelli O, et al. This is an open-access article distributed under the terms of the Creative Commons Attribution License, which permits unrestricted use, distribution, and reproduction in any medium, provided the original author and source are credited 
forms trimeric spikes on the virion envelope and it is responsible for virus adsorption on the cell membrane [3] (Figure 1a,1b).

The first case of filo virus haemorrhagic fever was reported in 1967 in Germany, following exposure of laboratory staff to C. aethiops biological fluids; the causative agent was identified as Marburg virus [3]. Similar cases of haemorrhagic fever were described in 1976 from outbreaks in two neighboring locations: first in southern Sudan and subsequently in northern Zaire [4]. An unknown causative agent was isolated from patients in both outbreaks and named Ebola virus. Two different subtypes of Ebola virus were involved into the outbreaks, afterwards classified as Zaire Ebola virus (EBOV) and Sudan Ebola virus (SUDV). Both viruses proved to be highly lethal ( $90 \%$ for the Zairian strain and 50\% for the Sudanese strain). The Taï Forest Ebola virus (TAFV) first emerged in Ivory Coast in 1994, was isolated from a man infected during the autopsy of a wild primate [3]. The last one Ebola virus subtype discovered, Bundibugyo Ebola virus (BDBV), appears during an outbreak in Uganda in 2007. An additional Ebola virus subtype, Reston Ebola virus (RESTV) was isolated in United States in 1989 from Philippines imported M. fascicularis [5]. BDBV, EBOV, and SUDV have been associated with large Ebola virus disease (EVD) outbreaks in Africa (Figure 2) [4]. Reston Ebola virus is the only one that seems to be asymptomatic in humans at the moment, but it has proved it can be fatal in monkeys and it has been recently recovered from infected swine in South-east Asia [6]. A detailed report of main Ebola virus outbreaks, divided according to Ebola virus subtypes, is shown in Table 1.

Human pathogenic Ebola virus (EBOV, SUDV, TAFV and BDBV) are endemic to Africa with an increase in the number of outbreaks and cases since 2000; the different subtypes of Ebola virus occurred with different frequencies (Table 1).

Filo virus haemorrhagic fever is thought to be a classic zoonosis with persistence of the Ebola virus in a reservoir species generally found in endemic areas. Although much effort has been made to identify the natural reservoirs, neither potential hosts nor arthropod vectors have been clearly recognized. The source of infection was originally identified in primates; however, they are susceptible to Ebola virus infection and

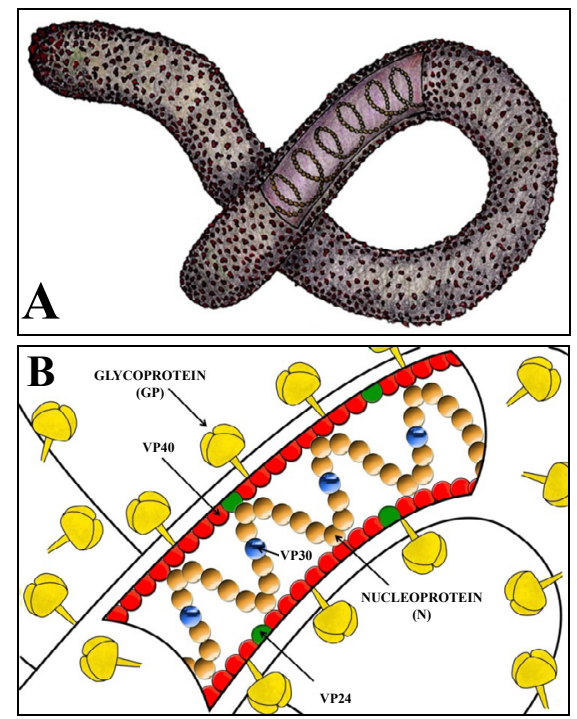

Figure 1: Graphical representation of Ebolavirus. A) Whole virion; gap shown the negative-sense RNA single-stranded genome. B) Detailed: main proteins of the virus are shown.

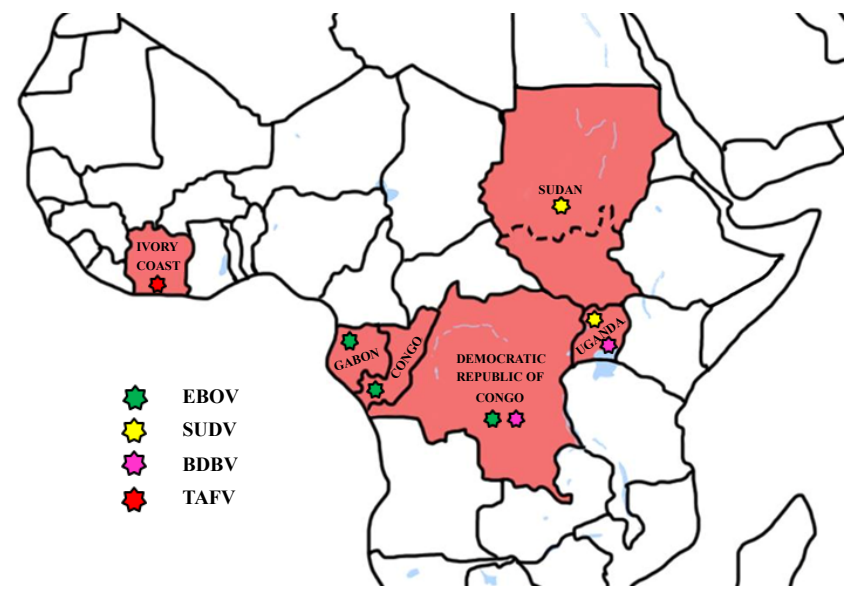

Figure 2: Countries affected by Ebolavirus outbreaks in Africa (in red). Colored asterisks match to different Ebolavirus subtypes in each region. Outbreaks between the appearance of the virus in 1976 and preceding the 2014 are considered.

\begin{tabular}{|c|c|c|c|c|}
\hline Year & Country & Cases & Fatality rate & References \\
\hline \multicolumn{5}{|l|}{ BDBV } \\
\hline 2012 & DRC & 57 & 0.51 & {$[\mathrm{~A}]$} \\
\hline \multirow[t]{2}{*}{2007} & Uganda & 149 & 0.25 & {$[\mathrm{~A}],[\mathrm{B}]$} \\
\hline & & 206 & 0.32 & \\
\hline \multicolumn{5}{|l|}{ SUDV } \\
\hline 2012 & Uganda & 7 & 0.57 & {$[\mathrm{~A}]$} \\
\hline 2012 & Uganda & 24 & 0.71 & {$[\mathrm{~A}]$} \\
\hline 2011 & Uganda & 1 & 1 & {$[\mathrm{~A}],[\mathrm{B}]$} \\
\hline 2004 & Sudan & 17 & 0.41 & {$[\mathrm{~A}],[\mathrm{B}]$} \\
\hline 2000 & Uganda & 425 & 0.53 & {$[\mathrm{~A}],[\mathrm{B}]$} \\
\hline 1979 & Sudan & 34 & 0.65 & {$[\mathrm{~A}],[\mathrm{B}]$} \\
\hline \multirow[t]{2}{*}{1976} & Sudan & 284 & 0.53 & {$[\mathrm{~A}],[\mathrm{B}]$} \\
\hline & & 792 & 0.54 & \\
\hline \multicolumn{5}{|l|}{ EBOV } \\
\hline 2008 & DRC & 32 & 0.46 & {$[\mathrm{~A}],[\mathrm{B}]$} \\
\hline 2007 & DRC & 264 & 0.71 & {$[\mathrm{~A}],[\mathrm{B}]$} \\
\hline 2005 & Congo & 12 & 0.83 & {$[\mathrm{~A}]$} \\
\hline 2003 & Congo & 35 & 0.83 & {$[\mathrm{~A}],[\mathrm{B}]$} \\
\hline 2003 & Congo & 143 & 0.9 & {$[\mathrm{~A}],[\mathrm{B}]$} \\
\hline 2001-2002 & Congo & 58 & 0.75 & {$[\mathrm{~A}],[\mathrm{B}]$} \\
\hline 2001-2002 & Gabon & 65 & 0.82 & {$[\mathrm{~A}],[\mathrm{B}]$} \\
\hline 1996 & South Africa & 2 & 0.5 & {$[\mathrm{~B}],[\mathrm{C}]$} \\
\hline 1996 & Gabon & 60 & 0.75 & {$[\mathrm{~A}],[\mathrm{B}]$} \\
\hline 1996 & Gabon & 31 & 0.68 & {$[\mathrm{~A}],[\mathrm{B}]$} \\
\hline 1995 & DRC & 315 & 0.81 & {$[\mathrm{~A}],[\mathrm{B}]$} \\
\hline 1994 & Gabon & 52 & 0.6 & {$[\mathrm{~A}],[\mathrm{B}]$} \\
\hline 1977 & DRC & 1 & 1 & {$[\mathrm{~A}],[\mathrm{B}]$} \\
\hline \multirow[t]{2}{*}{1976} & DRC & 318 & 0.88 & {$[\mathrm{~A}],[\mathrm{B}]$} \\
\hline & & 1388 & 0.79 & \\
\hline
\end{tabular}

Table 1: Ebolavirus outbreaks, divided respect main Ebolavirus subtypes Outbreaks between the appearance of the virus in 1976 and preceding the 2014 are considered. BDBV, Bundibugyo Ebolavirus: SUDV, Sudan Ebolavirus, EBOV, Zaire Ebolavirus. [Sources: A. World Health Organization (WHO). Media Center: Ebolavirus disease. Fact sheet $N^{\circ}$ 103. Updated April 2014. http://www.who.int/ mediacentre/factsheets/fs 103/en/; B. Centers for Disease Control and Prevention (CDC), Chronology of Ebola Hemorrhagic Fever Outbreaks. Known Cases and Outbreaks of Ebola Hemorrhagic Fever, in Chronological Order http://www.cdc. gov/vhf/ebola/resources/outbreak-table.html; C. World Health Organization (WHO) (1996) Weekly Epidemiological Record. 71: 353-360 http://www.who.int/docstore / wer/pdf/1996/wer7147.pdf]. 
are actually regarded as end hosts similarly to humans [7]. Analyses carried out on different animal's species during Ebola virus outbreaks seemed to designate particular species of fruit bats as putative virus reservoir. These animals show an asymptomatic infection that can be spread to other animals and humans through blood or other fluids, and also through handling and consumption of hunted bats in many rural villages [8]. The identification and successful isolation of Cuevavirus from the cave-dwelling Schreiber's bats in Europe further supports the hypothesis of bats as a reservoir species for filoviruses [9].

Epizootic infections with Ebola virus appear sporadically and occur in rural forested areas in equatorial Africa through direct contact with the blood, secretions, organs or other body fluids of infected animals [4]. After initial spillover event, outbreaks are primarily the result of person-to-person transmission of virus, which occurs through direct contact with infected individuals, their body fluids (saliva, stool, urine, and semen) or contaminated clothes or linens. Although airborne transmission among humans has not been reported [10], the potential ability of Ebola virus to infect the respiratory tract of non-human primates through aerosolized virus particles administration, has been clearly demonstrated [11].

Family members and health workers have the highest risk of Ebola virus spreading as a result of ill care. Religious practices during burial ceremonies can be also part of the Ebola virus spread in mourners and community members. World Health Organization (WHO) suggests that people deceased as consequence of EVD must be handled using protective clothing and gloves, and be buried immediately after death [4]. During outbreaks, patients isolation and use of the provided protective clothing and disinfection procedures is mandatory and it has been sufficient to interrupt further transmission of Ebola virus, and thus to control and end the outbreak [12]. Though the different subtypes of Ebola virus seem to cause somewhat different clinical syndromes, generally, the abrupt onset of EVD follows an incubation period of 2-21 days and is characterized by fever, headache, joint and muscle aches, sore throat, and weakness, followed by diarrhea, vomiting, and stomach pain. Only at the onset of symptoms, infected people become contagious. Haemorrhagic manifestations arise during the peak of the illness and include ecchymosed, mucosal hemorrhages, and post-mortem evidence of visceral haemorrhagic effusions [13]. In later stages, shock, convulsions, severe metabolic disturbances, and, in more than half the cases, diffuse coagulopathies.

Patients, who eventually recover, present fever for about five to nine days; convalescence is prolonged and sometimes associated with myelitis, recurrent hepatitis, psychosis or uveitis [3]. In fatal cases, death occurs between 6 and 16 days after the onset of symptoms that occur at an early stage, as a result of multi-organ failure and hypovolemic [14]. Ebola infection can be confirmed through several types of laboratory tests: ELISA, Real Time RT-PCR, antigen detection tests or serum neutralization test [4] executed only in laboratories provided with specific equipments [3]. Filoviruses are classified as Biological Level 4 (BSL4) agents by Health and Safety Executive [15] and as category A biological warfare agents (BWA) by the Centers for Disease Control and Prevention [16]. The nature of the virus make it suitable as BWA for the high lethality in human infection and for the potential oral and conjunctival viral transmission demonstrated with aerosolized virus suspensions in non-human primates [17]. This implies rigorous controls for diagnostic and research laboratories to prevent the access to the virus by terrorist organizations [18].

The high mortality associated to EVD represents an auto limitation for the virus expansion; that's why most of the outbreaks began and ended in rural areas.

The new outbreak of Ebola virus in West Africa in 2014 involves not only rural areas, but also the state capital of Guinea, the city of Conakry. The possible spread of Ebola virus disease in a high density population area is not the only worrying situation; the access to air travel could lead to a catastrophic scenario with possible outbreaks all over the world.

\section{Aviation as potential global spread}

On an international level several regulations, guidelines and recommendations relating to the management of transmissible diseases through air travel were published. Among them, the most important reference is represented by the International Health Regulations (IHR) adopted by the World Health Organization [19]. This document, focuses on the alert and response to outbreaks by public health, aims to identify, reduce or eliminate sources of infection or contamination related to air travels. In the presence of a public health emergency of international concern, WHO may issue recommendations (permanent or ordinary), which can include health measures regarding persons, baggage, containers, conveyances, goods, and/or parcels to avoid or reduce the spread.

WHO recommendations relating to passenger and aeronautical workers may include specific health measures, such as checking the travel history in affected areas, requests for medical examinations and laboratory tests, immunization requirements or other prophylaxis, observation, quarantine or public health measures for the suspects (isolation, identification of contacts of people with suspected and/ or restrictions on persons from affected areas). In the IHR measures on arrival and departure that a State may require for public health reasons are also reported. Depending on requirements, the competent authority may take additional health measures.

Other significant international references are represented by the "Airport Preparedness Guidelines for Outbreaks of Communicable Disease", published by the International Civil Aviation Organization (ICAO) and by the Airports Council International (ACI) [20]. This publication provide suggestions on the preparation of the airports in response to public health emergencies epidemic, tracing the key points, including internal and external communications; screening and monitoring the arrival and departure of travelers; logistics (organization of the transfer of passengers to health facilities); instrumental resources and coordination with local and national health authorities.

In Europe, an important contribution is provided by the European Centre for Disease Prevention and Control (ECDC) which, with the technical report "Risk Assessment Guidelines for Infectious Diseases transmitted on Aircraft" (RAGIDA) (ECDC, 2009) [21] and with the guidance "Risk Assessment Guidelines for Diseases transmitted on Aircraft (RAGIDA). Part 2: Operational guidelines for assisting in the evaluation of risk for transmission by disease" (ECDC, 2010) [22] traces, for some of the most important transmissible diseases, the main characteristics, the routes of exposure and the procedures to be adopted in the immediate and in the post-exposure, especially in reference to the problem of traceability of possible peoples contacts.

For the health security, airplanes are generally more secure than other transportation, mainly for the hygiene and salubrity of the air, thanks to high-efficiency air filters. Nevertheless, the spread of several diseases has been demonstrated aboard aircraft; more than ten relevant for transmission diseases (Tuberculosis, Influenza, SARS, 
Meningococcal disease, Measles, Rubella, Diphtheria, Ebola, Marburg, Lassa, Smallpox, and Anthrax) are highlighted by ECDC [21].

In order to reduce the risk of not airborne (or not airborne only) pathogens transmission on the aircrafts as well in the shared spaces of the airports, frequent routine cleaning and disinfections using nondetrimental specific substances is mandatory [23].

The potential routes of transmission of infectious agents on board are mainly: a) inhalation of airborne droplets or small particles; b) direct contact with organic residues; c) indirect contact with respiratory secretions and other biological fluids contaminated surfaces.

In literature, several cases of aboard aircraft infection are reported. Two studies can be cited, the first one relating to a tuberculosis case [24] and the other one to a Severe Acute Respiratory Syndrome (SARS) case [25].

The cabin crew should be informed about the presence of any outbreaks or endemic diseases in places reached by the flight, about epidemiological characteristics of any pathogens and it should be made aware of the main symptoms of possible transmissible diseases present (fever, cough, sore throat, and sometimes vomiting and diarrhea, etc.).

The traceability of passengers exposed at the risk of infection during an air travel is extremely important in order to reduce the risk of spreading an infectious disease. Traceability should be started following a careful evaluation based on the infectivity of the patient, the effective amount of personal contacts and wherever possible, considering the individual susceptibility of the exposed individuals.

The RACIDA guidance published by ECDC in 2010 [22] supply the response criteria and the procedures relating to the most relevant human airborne diseases. These focus also on the opportunity to use the traceability of people exposed to biological events on the aircraft. The same criteria can be extended, with the appropriate adaptations, to other infectious diseases resulting from intentional events. The key points of RACIDA guidelines include, essentially, the definition of a) the index case (i.e. the case alleged, probable or confirmed infection starting); b) the exposure effective risk (which takes into account both the duration of the flight that the placement in the cabin) and c) the traceability criteria [22].

According to the IHR [19], in response to public health emergency events of international concern, the airports located in outbreaks involved areas must practice a screening of passengers. This task may play a key role in limiting the spread of a transmissible disease. The screening activity must also be considered as a function of the epidemiology and of the disease morbidity and mortality. The screening advantages appear evident for infectious diseases that can be transmitted during the incubation period or in the event of asymptomatic forms. Among the possible screening models should be cited: visual inspection, questionnaires, temperature measurement (thermal scanners and other available methods), to be calibrated according to the disease features.

The screening of passengers from affected areas is definitely more effective than the screening made on arrival; it results in a) lower number of travelers to be screened; $b$ ) increased probability that a positive result is a true positive; c) reduced transmission of pathogens on the aircraft.

\section{Ebola virus spread in 2014: potential involvement of aviation}

The Ebola virus outbreak in 2014 in West Africa represents the first documented outbreak in this geographical area [26]. The spread has involved more than one country: starting in early February from Guinea, it has rapidly reach places abroad, first of all Liberia (Figure 3). Also closest regions, Mali and Sierra Leone, reports suspected cases, many of whom afterwards proved negatives for Ebola virus [27] (Figure 4).

The etiology of the disease was first confirmed by the National Reference Centre for Viral Haemorragic Fevers of the Pasteur Institute in Lyon, France [26]. Genetic analysis of the West Africa Ebola virus emerged in 2014 indicates that is strictly homologous with the high case-fatality EBOV last reported in 2009 in Democratic Republic of Congo [26].

Since the beginning of outbreak of the Ebola virus, the Ministry of Health $(\mathrm{MoH})$ of Guinea, with the help of WHO and Médecins sans Frontières (MSF) is establishing treatment and isolation centers

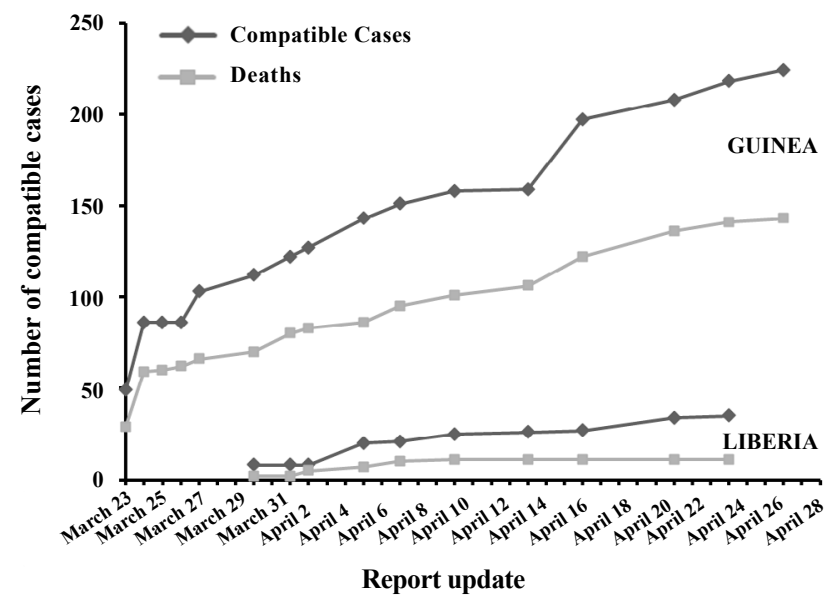

Figure 3: Time trend of compatible cases (confirmed cases and suspected cases) (dark gray line) and deaths related to compatible cases (light gray line) of Ebolavirus infection in Guinea and Liberia (Source: World Health Organization, WHO, Updated April, 2014. http://www.who.int/csr/don/archive/ disease/ebola/en/)

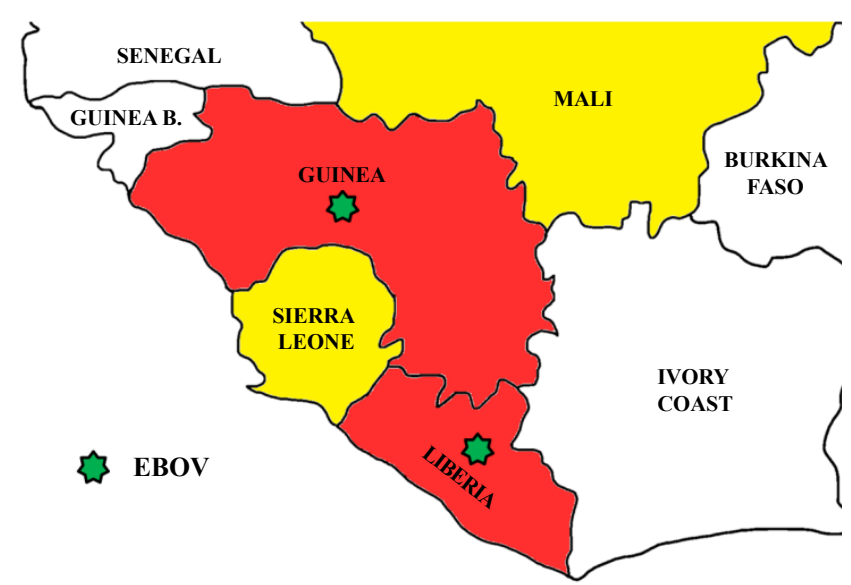

Figure 4: Distribution of Ebolavirus outbreak in West Africa from early 2014 Red color indicates the countries where the outbreak has been confirmed, Guinea and Liberia. Epidemics in neighboring countries, Sierra Leone and Mali (in yellow) have not been actually confirmed by laboratory tests. Green asterisk match to Ebolavirus subtype identified. 
in the epicenter of the outbreak. In Liberia, several international organizations, including the International Red Cross (IRC), are aiding the Ministry of Health and Social Welfare (MoHSW) by supporting awareness campaigns and providing personal protective equipment (PPE) (coveralls, gloves, surgical gowns, face shields, face masks, safety goggles, head covers, respirators, shoe covers, gum boots) for healthcare workers [28].

Centers for Disease Control and Prevention (CDC) deployed expert teams to assist WHO, Guinea $\mathrm{MoH}$ and Liberia MoHSW to improve international response to this Ebola virus outbreak. Implementation of the collaboration among institutes and laboratories (i.e. the Emerging and Dangerous Pathogens Laboratory Network) for diagnostic procedures was also carried on [29]. Certain provisions, including the banning of the bats meat consummation, were also imposed [30]. Senegal, a country neighboring Guinea, has closed its borders to limit the spread of the outbreak [26]. Several national Agencies, such as the Public Health Agency of Canada or the French Ministry of Health, have published issues and information about precautions to be taken for the tourists and commercial operators in hazardous areas [31,32].

The main concern of the International Agencies about the potential spread of Ebola virus in areas far away from the epicenter of the epidemic is mainly due to the reaching of clinical cases in an urban environment. This could represent a risk for the global spread if air travels are carrying out by affected individuals. As well documented, the infectivity of Ebola virus is limited to the symptomatic phase [33]. Due to the highly incapacitating symptoms of Ebola virus infection, the event that an affected individual undertake an air travel during the symptomatic phase results very unlikely. Moreover the symptomatic passenger boarding should be prevented by control measures put in place by the countries involved in the outbreak at the departure airports.

However, two risk events may occur and should be taken into consideration. The first event is represented by an individual who becomes symptomatic and therefore infectious aboard an airplane; the second event is represented by an individual who manifests symptoms after reaching at the destination.

In the case that a passenger manifests symptoms on aircraft, will be necessary to establish whether: a) he has visited a country where the Ebola virus spread has been confirmed in the previous three weeks and b) he has been in contact with wild sick or dead animals or persons [26].

In the presence of affirmative answers, the symptoms may actually be associated to EVD and the measures from RAGIDA report and guidance [22] and IATA Guidelines for Suspected Communicable Diseases [34] will be followed for the prevention of other passengers and crew health.

In particular, the IATA guidelines indicate what should be the management of the affected individual on board the aircraft. The affected must a) be kept separate from close contact with other passengers; b) be provided with a surgical mask in order to reduce the number of droplets emitted; the crew should use disposable gloves to avoid direct contact with body fluids. In the event of affected individuals, an accurate disinfection and sanitizing of aircraft and airports are essential, since biological fluids (urine, blood, saliva, etc.) dropped inside the aircraft or in the airport area represent a risk factor [21] due to the capacity shown by the virus to remain infectious for several days in liquid or dry media [35]. However, Ebola virus is easily inactivated by common disinfectants [36], thus the cleaning procedures currently used in airports and aircraft appear to be suitable for the virus removal. Special precautions (both about protective devices that about cleaning strategies) must be taken to avoid contaminations of the cleaning staffs [37]. As indicated by the RAGIDA guidance, passengers seated one seat apart from the infected traveler as well as crew and cleaning service members who have had direct contacts with body or bodily fluids of the affected individual should be monitored. The arrival airport must be alerted by the aircraft captain as soon as symptoms of disease are detected, in order to put in place the necessary measures for reception and medical assistance of the affected individual and people come in contact with him.

Different evaluations should be carried out considering the hypothesis that an incubating asymptomatic individual manifest symptoms after reaching him destination. Security measures at departure airports including temperature scan or symptoms tests are not effective in diagnosing of asymptomatic individual who could therefore easily pass medical controls and start a new focus of outbreak miles far away from the initial one. Therefore, for diseases characterized by a long incubation period, such as Ebola virus, it would be also opportune to implement screening procedures for all arriving passengers from epidemic areas, in order to identify any individuals who are developing symptomatic fever.

The indications about the management of a potential outbreak in far areas after the people movement from the arrival airport appear however to be limited to a few essential directions, such as the tracking of passenger flows and the importance of communication between affected person and the health authorities about the movements and interpersonal contacts [38]. Response procedures appear therefore to be delegated to the medical institutions (such as Department of Health, Ministry of Health, etc.) of potentially affected nations. The training of expert teams competent in epidemic management and in the development of intervention plans is also mandatory: in this direction the University of Rome Tor Vergata is working on the preparation of new experts and new ways to face and manage CBRN (Chemical, Biological, Radiological, Nuclear) events like the Ebola virus outbreak one [39-47].

\section{Conclusions and Discussion}

The Ebola virus outbreak in West Africa from early 2014, has turned on the spotlight on the problem of potential global diffusion of Ebola virus.

Ebola virus is considered one of the higher lethal pathogens however, and due to severe illness and the extremely high mortality rate, Ebola virus is considered a self-limiting spreading pathogen. It is infective only in the symptoms stage and diffusion during the incubation stages is not reported by the literature. Symptomatic individuals, due to the high pathogenesis, fail to leave the place of onset of symptoms.

The new outbreak in West Africa in the early 2014 is causing most concern since the epidemic is reaching of urban areas. This represents a novelty in the diffusion assessment due the density of population in the urban. In addition, it is easier for infected individual move in areas far away, as in the case of air travels. Although it is unlikely that an Ebola virus infected individual can board an aircraft during the symptomatic phase of EVD, the possibility that a disease incubating passenger may constitute a contagion hazard in the event that he manifests symptoms during the flight or in arrival destination areas cannot be ruled out.

In each potentially exposed country should therefore be present ad hoc designed emergency plans to be implemented in the event of 
outbreaks. In addition, health care professionals should be correctly trained and supplied with the necessary equipment in order to best manage the emergency. In view of the Ebola virus long incubation period, the traceability of passengers arriving from outbreak spread areas, using e.g. traceability cards (as performed during the SARS outbreak of in $2003[48,49]$ ) is strictly recommended for at least three weeks after arrivals. Passengers from at-risk areas should also be advised to be careful to the emergence of any potential symptom and response teams should be prepared in the occurrence of suspicious cases. The population should be informed about the most common symptoms and the references of the emergency response team should be indicated.

Preparation is mandatory to manage a possible, although unlikely, Ebola virus outbreak in places far away from origin areas. The underestimation of a possible threat can be dangerous, as well as an overestimation might be; therefore it is very important to properly assess the situation in order to avoid causing panic in the population, but at the same time be ready to counter any potential emergency.

\section{Addendum}

Due to the rapid evolution of the Ebola virus outbreak, all the data shown in this paper represents the situation at May $1^{\text {st }}, 2014$.

\section{Acknowledgements}

Special acknowledgements for the realization of this work go to the International Master Courses in "Protection against CBRNe events" (www.mastercbrn. com)

\section{References}

1. Feldmann H, Jones S, Klenk HD, Schnittler HJ (2003) Ebola virus: from discovery to vaccine. Nat Rev Immunol 3: 677-685.

2. Kuhn JH, Becker S, Ebihara H, Geisbert TW, Johnson KM, et al. (2010) Proposal for a revised taxonomy of the family Filoviridae: classification, names of taxa and viruses, and virus abbreviations. Arch Virol 155: 2083-2103.

3. Feldmann H, Klenk HD (1996) Filoviruses. In: Medical Microbiology. (4thedn), Baron S, edt. University of Texas Medical Branch at Galveston, Galveston, TX, USA.

4. World Health Organization (WHO) Media Center: Ebola virus disease. Fact sheet $\mathrm{N}^{\circ} 103$.

5. Reed Z (2012) A Historical Perspective and Review of the Evidence to Support Fruit Bats as the Natural Reservoir for Ebola Viruses. Georgia State University, USA, Public Health Theses, Paper 241.

6. Centers for Disease Control and Prevention (CDC) Viral haemorrhagic fevers (VSFs). Filoviridae.

7. Groseth A, Feldmann H, Strong JE (2007) The ecology of Ebola virus. Trends Microbiol 15: 408-416.

8. Leroy EM, Kumulungui B, Pourrut X, Rouquet P, Hassanin A, et al. (2005) Fruit bats as reservoirs of Ebola virus. Nature 438: 575-576.

9. Negredo A, Palacios G, Vázquez-Morón S, González F, Dopazo H, et al. (2011) Discovery of an ebolavirus-like filovirus in europe. PLoS Pathog 7: e1002304.

10. Feldmann H, Geisbert TW (2011) Ebola haemorrhagic fever. Lancet 377: 849862.

11. Johnson E, Jaax N, White J, Jahrling P (1995) Lethal experimental infections of rhesus monkeys by aerosolized Ebola virus. Int J Exp Pathol 76: 227-236.

12. Centers for Disease Control and Prevention (CDC) and World Health Organization (WHO) (1998) Infection Control for Viral Haemorrhagic Fevers in the African Health Care Setting. Centers for Disease Control and Prevention, Atlanta, USA, pp. 1-198.

13. Centers for Disease Control and Prevention (CDC) (2009) Ebola Hemorrhagic Fever Information Packet. Special Pathogens Branch.

14. Sanchez A, Geisbert TW, Feldmann H (2007) "Filoviridae: Marburg and Ebola
Viruses," In Fields Virology 5th edition. Knipe DM, Howley PM (Eds.), pp. 1409 1448. Lippincott-Williams \& Wilkins, Philadelphia.

15. Approved List of Biological Agents (2004) Advisory Committee on Dangerous Pathogens (ACDP). Health and Safety Executive (HSE), UK.

16. Buzard GS, Baker D, Wolcott MJ, Norwood DA, Dauphin LA (2012) Multiplatform comparison of ten commercial master mixes for probe-based real-time polymerase chain reaction detection of bioterrorism threat agents for surge preparedness. Forensic Sci Int 223: 292-297.

17. Lazarus AA, Decker CF (2004) Plague. Respir Care Clin N Am 10: 83-98.

18. Jaax NK, Davis KJ, Geisbert TJ, Vogel P, Jaax GP, et al. (1996) Lethal experimental infection of rhesus monkeys with Ebola-Zaire (Mayinga) virus by the oral and conjunctival route of exposure. Arch Pathol Lab Med 120: 140-155

19. Cenciarelli O, Rea S, Carestia M, D’Amico F, Malizia A, et al. (2013) Bioweapons and Bioterrorism: a review of History and Biological Agents. Defence S\&T Technical Bullettin, 6: 111-129.

20. World Health Organization (WHO) (2008) International Health Regulations (IHR) (2005). World Health Organization. WHO Press, II Edition, Geneve, Switzerland.

21. International Civil Aviation Organization (ICAO) and Airports Counci International (ACI) (2006) Airport preparedness guidelines for outbreaks of communicable disease.

22. European Centre for Disease Prevention and Control (ECDC) (2009) Technical Report - Risk Assessment Guidelines for Infectious Diseases transmitted on Aircraft (RAGIDA). ECDC, Stockholm, Sweden.

23. European Centre for Disease Prevention and Control (ECDC) (2010) Guidance - Risk Assessment Guidelines for Diseases transmitted on Aircraft (RAGIDA) PART 2: Operational guidelines for assisting in the evaluation of risk for transmission by disease. ECDC, II Edition, Stockholm, Sweden.

24. World Health Organization (WHO) (2009) Guide to hygiene and sanitation in aviation. World Health Organization. WHO Press, 3rd Edition, Geneve Switzerland

25. Kenyon TA, Valway SE, Ihle WW, Onorato IM, Castro KG (1996) Transmission of multidrug-resistant Mycobacterium tuberculosis during a long airplane flight N Engl J Med 334: 933-938.

26. Olsen SJ, Chang HL, Cheung TY, Tang AF, Fisk TL, et al. (2003) Transmission of the severe acute respiratory syndrome on aircraft. N Engl J Med 349: 24162422.

27. European Centre for Disease Prevention and Control (ECDC) (2014) Updated 8 April. Outbreak of Ebola virus disease in West Africa. ECDC, Stockholm.

28. Centers for Disease Control and Prevention (CDC). Ebola haemorrhagic fevers. Outbreak of Ebola in Guinea and Liberia.

29. Ministry of Health and Social Welfare of Liberia (MOHSW) (2014) Ebola outbreak Personal protective equipment (PPE) and containment equipment Equipment allocation schedule.

30. World Health Organization (WHO) Global Alert and Response (GAR). Ebola virus disease in Guinea.

31. BBC News Africa (2014) Guinea Ebola outbreak: Bat-eating banned to curb virus.

32. Public Health Agency of Canada (PHAC) Travel Health Notice-Ebola Outbreak in Guinea.

33. Ministère des Affaires sociales et de la Santé. Fièvre hémorragique à virus Ebola (French).

34. Colebunders R, Borchert M (2000) Ebola haemorrhagic fever-a review. J Infect 40: $16-20$.

35. International Air Transport Association (IATA) (2011) Suspected Communicable Disease-Health Guidelines for Cabin Crew.

36. Piercy TJ, Smither SJ, Steward JA, Eastaugh L, Lever MS (2010) The survival of filoviruses in liquids, on solid substrates and in a dynamic aerosol. J App Microbiol 109: 1531-1539.

37. Public Health Agency of Canada (PHAC) Ebola virus. Pathogen Safety Data Sheet-Infectious substances.

38. Centers for Disease Control and Prevention (CDC) Interim Guidance about 
Citation: Cenciarelli O, Pietropaoli S, Frusteri L, Malizia A, Carestia M, et al. (2014) Biological Emergency Management: The Case of Ebola 2014 and the Air Transportation Involvement. J Microb Biochem Technol 6: 247-253. doi:10.4172/1948-5948.1000152

Ebola Virus Infection for Airline Flight Crews, Cargo and Cleaning Personnel, and Personnel Interacting with Arriving Passengers.

39. European Centre for Disease Prevention and Control (ECDC) (2014) Ebola virus disease-Information to travellers.

40. Cenciarelli O, Malizia A, Marinelli M, Pietropaoli S, Gallo R, et al. (2013) Evaluation of biohazard management of the Italian national fire brigade. Defence S\&T Technical Bullettin 6: 33-41.

41. Gallo R, De Angelis P, Malizia A, Conetta F, Di Giovanni D (2013) Development of a georeferencing software for radiological diffusion in order to improve the safety and security of first responders. Defence S\&T Technical Bullettin 6: 2132.

42. Malizia A, Lupelli I, D'Amico F, Sassolini A, Fiduccia A (2012) Comparison of software for rescue operation planning during an accident in a nuclear power plant. Defence S\&T Technical Bullettin 5: 36-45.

43. Malizia A, Quaranta R, Mugavero R, Carcano R, Franceschi G (2011) Proposal of the prototype RoSyD-CBRN, a robotic system for remote detection of CBRN agents. Defence S\&T Technical Bullettin 4: 64-76.

44. Malizia A, Quaranta R, Mugavero R (2010) CBRN events in the subway system of Rome: Technical-managerial solutions for risk reduction. Defence S\&T
Technical Bullettin 2: 140-157.

45. Pazienza M, Britti MS, Carestia M, Cenciarelli O, D'Amico F, et al. (2013) Application of Real-Time PCR to Identify Residual Bio-Decontamination of Confined Environments after Hydrogen Peroxide Vapor Treatment: Preliminary Results. J Microb Biochem Technol 6: 24-28.

46. Pazienza M, Britti MS, Carestia M, Cenciarelli O, D'Amico F, et al. (2014) Use of Particle Counter System for the Optimization of Sampling, Identification and Decontamination Procedures for Biological Aerosols Dispersion in Confined Environment. J Microb Biochem Technol 6: 43-48.

47. Sassolini A, Malizia A, D’Amico F, Carestia M, Di Giovanni D, et al (2014) Evaluation of the Effectiveness of Titanium Dioxide (TiO2) Self-Cleaning Coating for Increased Protection Against CBRN Incidents in Critical Infrastructures. Defence S\&T Technical Bullettin 7: 9-17.

48. Cacciotti I, Aspetti PC, Cenciarelli O, Carestia M, Di Giovanni D, et al. (2014) Simulation of Caesium-137 (137Cs) Local Diffusion as a Consequence of the Chernobyl Accident Using Hotspot. Defence S\&T Technical Bullettin 7: 18-26.

49. European Commission, SANCO-Public Health Directorate, G4 UnitCommunicable, Rare and Emerging Diseases (2003) Measures undertajen by member states and accession countries to control the outbreak of SARS. 